\title{
LOS DAÑOS PUNITIVOS EN EL DEREGHO MEXICANO. ALGUNAS IDEAS PARA SU INTERPRETAGIÓN*
}

\author{
PUNITIVE DAMAGES IN MEXICAN LAW. SOME IDEAS \\ FOR ITS INTERPRETATION
}

\section{Jorge Eduardo Medina VillanueVA**}

RESUMEN: Recientemente, la Primera Sala ABSTRACT: Recently, the First Chamber of the Sude la Suprema Corte de Justicia de la Nación preme Court of Justice of the Nation issued a resoludictó una resolución en la que declaró la tion in which it declared the admissibility of puniadmisibilidad de los daños punitivos en tive damages in Mexican law, in matters of moral el derecho mexicano, en materia de daño damage. However, applying a detailed analysis of moral. Sin embargo, al aplicarlo un análisis the sentence, its arguments and grounds, leads us to detallado de la sentencia, sus argumentos y the conclusion that this figure has very little in comfundamentos, nos lleva a la conclusión de mon with the "punitive damages" applied in the que esa figura tiene muy poco en común con common law legal systems, and refers only to how los "punitive damages" aplicados en los sistemas to quantify the compensation awarded to the victim. jurídicos del common law, y se refiere únicamente a la forma de cuantificar la indemni- Keyzerds: Punitive Damages, Civil Responzación que se otorgue a la víctima. sability, Moral Damages, Tort Law.

Palabras clave: daños punitivos, responsabilidad civil, daño moral, derecho de daños.

* Artículo recibido el 5 de noviembre de 2019 y aceptado para su publicación el 5 de marzo de 2020.

** ORCID: 0000-0002-1755-7812. Profesor investigador de la Universidad Panamericana, Campus Guadalajara, Facultad de Derecho. Álvaro del Portillo 49, Zapopan, Jalisco, 45010, México. Correo electrónico:jemedina@up.edu.mx.

Boletín Mexicano de Derecho Comparado, nueva serie, año LII, núm. 157, enero-abril de 2020, pp. 221-242. 
Sumario: I. Introducción. II. Sintesis del caso. III. Punitive damages. IV. Análisis crítico. V. Bibliografia.

\section{INTRODUCGIÓN}

A principios de 2014, la Primera Sala de la Suprema Corte de Justicia de la Nación señaló en una ya famosa sentencia, que en materia de daño moral podrían ser aplicados los llamados "daños punitivos". Esta figura, hasta entonces desconocida en el panorama jurídico nacional, pareciera que se refiere, por su simple traducción literal, a los "punitive damages", los que tienen una larga tradición y construcción en los países del sistema del common law, principalmente en Inglaterra y Estados Unidos.

Debe resaltarse que el sistema jurídico mexicano en general se ubica en la tradición romano-canónica, o sea, en el sistema conocido como civil law. En el caso particular de la responsabilidad civil, se sigue la corriente francesa, es decir, considerando la atipicidad del hecho ilícito y admitiendo la indemnización de los daños morales. No obstante, esta pertenencia al sistema romano-canónico no ha sido impedimento para el trasplante de algunas figuras jurídicas de la tradición del common law, como aparentemente es el caso que aquí se comentará (Muñoz y Vázquez-Cabello 2019).

Sin embargo, tras una lectura desapasionada y cuidadosa de las tesis emitidas por la Primera Sala y de la propia sentencia que les da origen, podemos concluir que los daños punitivos que nuestro máximo tribunal pretende introducir tienen muy poco en común con los mencionados punitive damages, ya que según se argumentará en el presente trabajo, lo que propone la Primera Sala es que se considere la conducta del responsable como un elemento para la cuantificación del daño moral, atento a lo ordenado por el artículo 1916 del Código Civil para el Distrito Federal.

Para desarrollar estas ideas, analizaremos primeramente en forma breve la sentencia relativa a la reclamación de indemnización por daño moral que presentan los padres, ocasionado por la trágica muerte de su hijo, un muchacho de 23 años, y nos concentraremos en la forma en que la Suprema Corte estableció que debía ser calculada la indemnización a pagar a los padres de la víctima (Amparo directo 30/2013, de 26/02/2014; en adelante, $\mathrm{AD} 30 / 2013$ ).

Luego, se hará una breve relación de la forma en que la jurisprudencia inglesa y estadounidense han abordado el tema de los punitive damages, 
para posteriormente analizar la correspondencia o no entre ellos y la figura a que se refiere la Primera Sala de nuestro máximo tribunal.

\section{SÍNTESIS DEL CASO}

El asunto que da origen al tema materia del presente trabajo es el Amparo directo 30/2013 de la Primera Sala de la Suprema Corte de Justicia de la Nación, resuelto en sesión del 26 de febrero de 2014, bajo la ponencia del ministro Arturo Zaldívar Lelo de Larrea.

Los hechos del caso son que, en septiembre de 2010, la víctima - un joven de 23 años, recién egresado de la licenciatura en administración de tecnologías de la información - acudió con sus amigos al puerto de Acapulco, Guerrero, a celebrar las fiestas patrias por el bicentenario de la Independencia. El 16 de septiembre, al estar a bordo de un kayak en el lago artificial del hotel, cayeron la víctima y su novia al agua, cuando ésta se encontraba electrificada. Los amigos intentaron salvarlos; sin embargo, sólo la novia pudo subirse de nuevo al kayak. Después de 20 o 25 minutos, los empleados del hotel lograron desconectar la energía eléctrica, no obstante que de inmediato habían sido notificados del suceso por los huéspedes. En este lapso, la víctima continuó dentro del agua, pues quienes intentaban rescatarlo no podían, por sufrir fuertes descargas eléctricas.

Una vez apagada la electricidad, sacaron a la víctima del agua, y los huéspedes del hotel, que se ostentaron como médicos le dieron los primeros auxilios. Después, trasladaron a la víctima a la clínica del hotel, donde la doctora de guardia le proporcionó la atención médica. Entre 30 y 60 minutos tardó en llegar la ambulancia; sin embargo, se acreditó en el proceso que al momento en que ésta llegó al hotel, la víctima ya había fallecido, a causa de electrocución en conductor húmedo (agua).

Como consecuencia de ello, los padres de la víctima interpusieron una demanda de responsabilidad civil en contra del hotel, reclamando una indemnización por el daño moral causado. Después de seguir la secuela procesal correspondiente, llegó el asunto a la Primera Sala de la Suprema Corte de Justicia de la Nación, donde se emitió la sentencia materia del presente trabajo.

Ahora bien, la sentencia del Amparo directo 30/2013, materia de este estudio, retomando la doctrina y la constante jurisprudencia de la propia Corte, realiza el estudio de la procedencia de la responsabilidad civil ana- 
lizando sus tres elementos tradicionales, los cuales son abordados de la siguiente manera:

\section{Hecho ilícito}

La sentencia señala que es necesario para que surja la responsabilidad civil extracontractual, como en el presente caso, "el comportamiento negligente de la persona obligada a indemnizar” (AD30/2013, 58), y agrega que "la conducta del responsable será ilícita cuando incumpla con alguna obligación legal a su cargo" (AD30/2013, 58), y

... la conducta también será ilícita cuando el responsable sea negligente. La negligencia presupone un deber de cuidado incumplido, es decir, que el quejoso (quizá debió de haber dicho el demandado o el causante del daño) deja de realizar aquellos actos de cuidado a los que se encuentra obligado, causándose así un daño (AD30/2013, 58).

Respecto al tema de las obligaciones legales a cargo del hotel demandado, la sentencia establece que en el presente caso se incumplieron las establecidas en:

- Artículo 61, IV, de la Ley General de Turismo. ${ }^{1}$

- Artículo 1, fracción I, de la Ley Federal de Protección al Consumidor. $^{2}$

- La Norma Oficial Mexicana NOM-011-TUR-2001, requisitos de seguridad, información y operación que deben cumplir los presta-

1 Los turistas, con independencia de los derechos que les asisten como consumidores, tendrán en los términos previstos en esta Ley, los siguientes derechos: IV. Recibir del prestador de servicios turísticos, los bienes y servicios de calidad, acordes con la naturaleza y cantidad de la categoría que ostente el establecimiento elegido.

2 Son principios básicos en las relaciones de consumo: I. La protección de la vida, salud y seguridad del consumidor contra los riesgos provocados por productos, prácticas en el abastecimiento de productos y servicios considerados peligrosos o nocivos.

Esta obra está bajo una Licencia Creative Commons

Atribución-NoComercial-SinDerivar 4.0 Internacional, IIJ-UNAM.

Boletín Mexicano de Derecho Comparado, núm. 157, enero-abril de 2020, pp. 221-242. 
dores de servicios turísticos de Turismo de Aventura, en particular los artículos $5.1^{3}$ y $6.1 .^{4}$

Además de lo anterior, de los hechos considerados como probados por la Suprema Corte, se observa que la demandada desplegó una serie de conductas ilícitas por negligentes, que se sintetizan de la siguiente manera a partir de la página 72 de la sentencia:

a) mantenimiento insuficiente de las instalaciones y omisión de medidas de seguridad en su uso. La empresa demandada omitió el mantenimiento adecuado de las instalaciones y medidas de seguridad para verificar que el lago artificial del hotel se encontrara en las condiciones óptimas para su uso, y que de esta manera no significara un riesgo para los usuarios. La sentencia señala que "Si la empresa hubiera cumplido con los deberes que tenía a su cargo, entre otros, si hubiere dado mantenimiento a la bomba de agua, el lago artificial jamás habría estado electrificado, evitándose así la muerte" (AD30/2013, 56);

b) omisión de capacitación del personal; la empresa demandada omitió la capacitación del personal ante el riesgo que significa las actividades acuáticas dentro de las instalaciones, lo cual quedó evidenciado con los siguientes elementos:

i) ineficaz respuesta del personal del hotel, pues no actuó con diligencia en auxiliar a la víctima, ya que la energía eléctrica se cortó y fue sacada la víctima del lago en un periodo de entre 20 y 30

3 El prestador de servicios turísticos debe observar las medidas de seguridad antes y durante la prestación del servicio, a efecto de brindar mayor seguridad a la integridad física del turista conforme a los términos previstos en esta norma, para lo cual los prestadores de servicios turísticos de turismo de aventura deben ofrecer a la llegada del turista toda la información respectiva.

4 Para desempeñar este tipo de actividades, los prestadores de servicios turísticos deben contar con lo siguiente: a) programas de capacitación y actualización para el personal por cada una de las actividades que se ofrecen, en los cuales, además de contemplar los temas relevantes de la actividad propia, se consideren aspectos sobre los recursos naturales y patrimonio cultural; b) manuales de seguridad y atención de emergencias por cada actividad que se ofrece; c) seguros contra accidentes y gastos médicos; d) reglamento interno; e) manuales de operación para los guías; f) programa y bitácora de mantenimiento del equipo utilizado en cada actividad. 
minutos, lo que demuestra que no existía protocolo de actuación ni capacitación ni instrucción suficiente para actuar frente a una eventualidad;

ii) atención médica inadecuada; no había personal en el lago para brindarle los primeros auxilios, no obstante que habían pasado entre 20 y 30 minutos, "de esta manera, la atención médica que se le pudo brindar fue hasta que lo trasladaron a la clínica del hotel" (AD30/2013, 74), y

c) conducta de la empresa frente a la eventualidad; no se brindó trato digno a los familiares, no informó el médico del hotel que el joven no presentaba signos vitales; nadie los acompañó al hospital, "ni tampoco algún acercamiento para tratar de verificar el estado de salud de la víctima” (AD30/2013, 75).

\section{Daño moral}

La sentencia se basa en la primera parte del artículo 1916 del Código Civil para el Distrito Federal, que indica que "Por daño moral se entiende la afectación que una persona sufre en sus sentimientos, afectos, creencias, decoro, honor, reputación, vida privada, configuración y aspecto físicos, o bien en la consideración que de sí misma tienen los demás". En el caso concreto, éste consistió en la afectación a los sentimientos y afectos de los promoventes del juicio - ambos padres-, por la muerte de su hijo lo cual, además de ser acreditado por la presunción de que la víctima era el hijo único de los actores, se probó directamente con los dictámenes sicológicos derivados del fallecimiento de su hijo; "por lo tanto - establece la sentencia en comento - se tiene plenamente probado el daño en sus afectos y sentimientos" (AD30/2013, 80).

\section{Nexo causal}

Señala la sentencia que el tercer elemento de la responsabilidad civil consiste en que el daño debe ser una consecuencia del hecho ilícito que se atribuye al demandado, de manera que "es necesario que el daño ex- 
perimentado sea consecuencia de la conducta del agente" (AD30/2013, 80-81).

Dice la sentencia que

en el caso, el daño consistió en la afectación en los sentimientos de los actores derivada de la muerte de su hijo victima, la cual se produjo porque el lago donde cayó se encontraba electrificado debido a la conducta negligente de la empresa, consistente en no dar mantenimiento a la bomba que provocó que se electrificara el lago. Por tanto, es claro que la relación entre el hecho ilícito y el daño se encuentra plenamente acreditada (AD30/2013, 82).

\section{Introducción de los daños punitivos}

Ahora bien, una vez acreditados los elementos de la responsabilidad civil, la sentencia procede a determinar el monto de la compensación derivada del daño moral, y es aquí donde introduce el tema de los "daños punitivos".

Debe aclararse que es la primera sentencia que trata el tema de los daños punitivos en México, y así, introduce al debate jurídico nacional y esta fisura reconoce inclusive de forma implícita la propia sentencia la originalidad.

Para analizar cómo es que la sentencia introduce los daños punitivos y qué entiende por ellos, debemos considerar conjuntamente las tesis que generó el asunto que tienen relación con el tema ${ }^{5}$ y el texto de la resolución.

La primera tesis (número 2006958, 2014) señala:

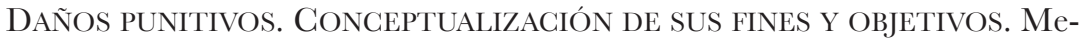
diante la compensación del daño se alcanzan objetivos fundamentales en materia de retribución social. En primer lugar, al imponer a la responsable la obligación de pagar una indemnización, la víctima obtiene la satisfacción de ver sus deseos de justicia cumplidos. Así, mediante la compensación, la víctima puede constatar que los daños que le fueron ocasionados también tienen consecuencias adversas para el responsable. Por otra parte, la compensación

5 El asunto generó 20 tesis; sin embargo, solamente tres tienen relación con el tema de los daños punitivos. 
tiene un efecto disuasivo de las conductas dañosas, lo que prevendrá conductas ilícitas futuras. Así, dicha medida cumple una doble función, ya que las personas evitarán causar daños para evitar tener que pagar una indemnización y, por otra, resultará conveniente desde un punto de vista económico sufragar todos los gastos necesarios para evitar causar daños a otras personas. A dicha faceta del derecho de daños se le conoce como "daños punitivos" y se inscribe dentro del derecho a una "justa indemnización".

Desgraciadamente, de su lectura no se desprende una clara conceptualización de los mismos, por lo que analizando y sintetizando lo que la sentencia señala entre sus páginas 83 y 91, podemos obtener lo siguiente:

La sentencia señala en la parte conducente que la indemnización a cuyo pago se condena como compensación por los daños ocasionados tiene dos aspectos:

a) a través de ella se alcanzan objetivos fundamentales en materia de retribución social, pues "mediante la compensación la víctima puede constatar que los daños que le fueron ocasionados también tienen consecuencias adversas para el responsable";

b) efecto disuasivo de la compensación, pues señala que debe ser más barato prevenir que indemnizar. Es aquí donde se inserta la faceta que se conoce como "daños punitivos", desaprobando a las personas que actúan ilícitamente, según lo señala en su parte final la tesis arriba anotada.

Deben señalarse dos aspectos, según indica la sentencia:

1) En ocasiones, limitar el pago de los daños a su simple reparación significaría que el responsable se enriquezca a costa de la víctima: ${ }^{6}$ "lo anterior en tanto las conductas negligentes en muchas ocasiones pretenden evitar los costos de cumplir con los deberes que exigen tanto la ley como los deberes generales de conducta" (AD30/2013, 88).

6 La doctrina francesa habla de faute lucrative - culpa lucrativa-, una culpa donde las consecuencias rentables para su autor no son neutralizadas por una simple reparación de los daños causados; lo que se propone en Francia es que la indemnización considere las ganancias ilícitas (Viney y Jourdain 2010). 
2) Los daños punitivos tienden a prevenir hechos similares en el futuro, imponiendo incentivos negativos para que se actúe con la debida diligencia.

Para fundamentar estos daños punitivos, la sentencia lo hace en el artículo 1916, cuarto párrafo, del Código Civil del Distrito Federal, que señala: "El monto de la indemnización lo determinará el juez tomando en cuenta los derechos lesionados, el grado de responsabilidad, la situación económica del responsable, y la de la víctima, así como las demás circunstancias del caso". Es aquí donde se inserta la segunda tesis (número 2006959, 2014):

DAÑOS PUNITIVOS. ENGUENTRAN SU FUNDAMENTAGIÓN LEGAL EN EL ARTÍCUlo 1916 DEL CÓdigo Givil PARA EL Distrito FEDERAL. El carácter punitivo de la reparación del daño se deriva de una interpretación literal y teleológica del artículo 1916 del Código Civil para el Distrito Federal. Dicho artículo dispone que en la determinación de la "indemnización", se valoren, entre otras circunstancias, los derechos lesionados, el grado de responsabilidad y la situación económica de la responsable. De esta forma, el juez no debe solamente considerar en su condena aquellos aspectos necesarios para borrar, en la medida de lo posible, el daño sufrido por la víctima, sino que existen agravantes que deberán ponderarse en el quántum de la indemnización. Como se puede observar, este concepto no busca únicamente reparar el daño en los afectos de la víctima, sino que permite valorar el grado de responsabilidad de quien causó el daño. Tal conclusión también se deriva de los antecedentes legislativos que dieron lugar a la reforma publicada en el Diario Oficial de la Federación el 31 de diciembre de 1982.

De esta forma, dice la sentencia, cuando el Código establece que deberán considerarse para cuantificar la indemnización, entre otros aspectos, el grado de responsabilidad del causante, es una forma de "sancionar al culpable".

Debemos hacer aquí una precisión importante, sobre la que ahondaremos líneas más adelante, relativa a que los "daños punitivos" que plantea la Suprema Corte de Justicia de la Nación corresponde a un aspecto a considerar para la cuantificación de la indemnización. Esto es, el artículo 1916 transcrito líneas arriba, señala varios aspectos que debe el juez con- 
siderar para determinar el monto de la indemnización, y entre ellos se encuentra el grado de responsabilidad.

Esta parte de la indemnización no enriquece injustamente a la víctima, según señala la tercera tesis (número 2006805, 2014):

INDEMNIZACIÓN POR DAÑOS. EL GARÁGTER PUNITIVO DE LA REPARAGIÓN NO ENRIQUECE INJUSTAMENTE A LA VÍGTIMA. Una indemnización que tenga en cuenta además del daño sufrido, el grado de responsabilidad del causante, no enriquece injustamente a la víctima. En efecto, el enriquecimiento ilegítimo tiene como presupuesto que no exista alguna causa legítima para enriquecerse, siendo que en el caso la compensación se encuentra plenamente justificada a partir del derecho a una justa indemnización. Dicho derecho ordena que todas las personas que sufran daños sean resarcidas integralmente, por lo tanto, si al tomar en cuenta el grado de responsabilidad del causante se busca resarcir plenamente a la víctima, dicha indemnización se encontrará plenamente justificada.

Esto lo hace sin duda la Primera Sala "curándose en salud", pues es uno de los argumentos más comunes esgrimidos en contra de los daños punitivos.

Termina el apartado de la sentencia diciendo: "En conclusión, el monto de la indemnización que se fije como compensación por el daño sufrido por la víctima debe ser suficiente para resarcir dicho daño y reprochar la indebida conducta del responsable" (AD30/2013, 91).

Con todo lo anterior, podemos concluir provisionalmente algunos puntos. Primero, la figura jurídica de los "daños punitivos" a que se refiere la Primera Sala de la Suprema Corte de Justicia de la Nación sólo aplica en materia de daño moral, al tener su fundamento en el artículo 1916 del Código Civil para el Distrito Federal. Segundo, que los "daños punitivos" a que se refiere la sentencia consisten en apreciar la conducta del demandado para calcular el monto de la indemnización por daño moral, ya que "en la determinación del quántum compensatorio también deberá valorarse el grado de responsabilidad de la parte demandada, así como el aspecto social del daño causado, esto es, la relevancia o implicaciones sociales que puede tener el hecho ilícito" (AD30/2013, 94).

Como consecuencia de lo anterior, el monto de los "daños punitivos" no se determina de forma independiente y separada del resto de la indemnización; es decir, de la parte puramente compensatoria de la condena, 
pues de hecho ni siquiera se determina o cuantifica esa "parte punitiva", lo cual es resaltado en los votos concurrentes a la sentencia, formulados por los ministros Cossío y Pardo, pues, por el contrario, la "parte punitiva" es un concepto - entre otros - que integra el monto de la cantidad total a pagar por concepto de indemnización compensatoria.

Así las cosas, pareciera que la sentencia pretende hacer alusión a la figura de los punitive damages que se aplica en los países de tradición jurídica anglosajona, pues al menos el término corresponde a la traducción literal de la expresión utilizada por la sentencia y las tesis: "daños punitivos".

\section{PUNITIVE DAMAGES}

Primeramente, debemos aclarar que el término punitive damages no hace referencia a una figura homogénea dentro de los países del sistema jurídico del common law, sino que, por el contrario, cada país ha ido desarrollando una visión propia de los mismos, con diferentes alcances y límites; sin embargo, poseen algunos elementos comunes. En términos generales, los punitive damages son aquellos daños que se condenan cuando la conducta del demandado ha sido tan indignante - ya sea por la forma en que se comportó al momento de cometer el hecho generador de responsabilidad, o por su conducta posterior - que amerita una sanción (Brooke 2009). De forma semejante, Prosser (2010) indica que consisten en una suma adicional, por encima de la compensación por el daño sufrido, otorgada con el propósito de castigar al demandado o amonestarlo, para que no vuelva a cometer la conducta y para disuadir a otros a seguir su ejemplo.

Esto es, los daños punitivos son aquellos que se otorgan por encima de lo necesario para compensar al reclamante. Al otorgar una indemnización por daños punitivos, además de hacer su desaprobación de su comportamiento, el juez o el jurado buscan principalmente castigar al acusado y disuadir a él y a otros de una conducta extraña similar (Wilcox 2009), es una sanción con fines ejemplarizantes (García y Herrera 2003, 213).

Se condenan estos daños en aquellos casos donde se considera que la mera compensación es insuficiente, casos en donde la conducta del demandado ha sido tan indignante que amerita que se castigue (Brooke 2009), de manera que se busca sancionar al dañador que actuó consciente o gravemente imprudente en la violación de los derechos del otro (McBride y Bagshaw 2018). Dicen García y Herrera que "el daño punitivo tiene 
como propósito castigar a quien produce un mal y disuadir tanto al causante del perjuicio como a otros posibles infractores de repetir la misma acción dañina, es decir, el daño punitivo se toma más como una sanción que como una indemnización" (García y Herrera 2003, 215), de manera que sólo se puede otorgar una indemnización por daños punitivos si el monto que se otorga en concepto de compensación es insuficiente para servir como castigo y compensación (Wilcox 2009).

Esta figura hace su aparición en Inglaterra en 1760, durante una serie de casos, donde el gobierno trató de suspender la publicación de un periódico asociado a un político de la época. Los abusos sufridos en las injerencias ilícitas de la autoridad de los funcionarios públicos y en ausencia de una ley específica, los jueces ingleses otorgaron daños no compensatorios, sin preocuparse demasiado por su clasificación (Brooke 2009).

Para efectos del presente trabajo, consideraremos exclusivamente para su análisis, la regulación de los punitive damages en Inglaterra y en Estados Unidos; unos, por ser los primeros que surgieron, y por ser una referencia en los países del common law, y los otros, por ser nuestro país vecino del norte, más cercando físicamente y con cierta influencia jurídica sobre nuestro entorno.

\section{Punitive damages en Inglaterra}

Sin detenernos en la evolución histórica de los punitive damages, pues excedería los límites de este trabajo, podemos decir que la reglamentación actual de los punitive damages o exemplary damages, como suelen ser denominados en Inglaterra, deviene principalmente del caso Rookes vs. Barnard (1964) de la House of Lords, que estableció sus límites y requisitos (Wilcox 2009).

Según esta sentencia, una condena por exemplary damages solamente procede en los siguientes casos:

a) el demandado es un ente público y actuó de una forma arbitraria, opresiva o inconstitucional, al causar el daño; ${ }^{7}$

7 Nótese que, en nuestro país, ambas salas de la Suprema Corte de Justicia se han pronunciado en contra de la procedencia de los daños punitivos en los casos en que el Estado es el demandado. Véase la tesis 2018607: Daños PUNITIVOS. Es INAPLICABLE

Esta obra está bajo una Licencia Creative Commons

Atribución-NoComercial-SinDerivar 4.0 Internacional, IIJ-UNAM.

Boletín Mexicano de Derecho Comparado, núm. 157, enero-abril de 2020, pp. 221-242. 
b) el demandado causó el daño porque calculó que haría más dinero cometiendo el daño que el que pagaría en una indemnización, es decir, su ganancia es superior a la indemnización que eventualmente pagaría. Para esto, la House of Lords dijo:

Cuando un acusado con un cínico desprecio por los derechos de un demandante ha calculado que el dinero que se obtendrá de su delito probablemente superará los daños en riesgo, es necesario que la ley demuestre que no se puede romper con impunidad (Rookes vs. Barnard 1964).

La sentencia señaló que deben considerarse tres situaciones al momento de calcular la condena por exemplary damages. ${ }^{8}$

a) el demandante debe ser víctima de una conducta punible, es decir, una conducta jurídica y socialmente reprochable;

b) el principio de moderación. El monto debe ser el mínimo necesario para mantener el propósito de los daños: castigar y disuadir, ya que los exemplary damages son un arma para proteger la libertad, y no debe ser usada contra ella, y

c) los medios (posibilidades) económicas del demandado, a fin de que sea una cifra proporcional a sus circunstancias económicas concretas.

En palabras de Salvador, este caso de 1964 casi declara abolidos los punitive damages, "por considerarlos incompatibles con la naturaleza estrictamente compensatoria de la indemnización de daños y perjuicios" (Salvador 2000, 5).

Adicionalmente, la sentencia Rookes vs. Barnard (1964) realizó una interesante distinción entre los exemplary damages y los aggravated damages. Éstos, al contrario de los exemplary, son considerados compensatorios, y procede su condena cuando el dañante demostró una conducta arrogante y arbitraria, ya sea en el momento de cometer los daños o en la forma en que trató a la víctima después de cometido el daño (McBride y Bagshaw 2018).

ESTA FIGURA EN LOS CASOS EN QUE EL ESTADO ES LA PARTE DEMANDADA; y en casos de responsabilidad pública, véase 2017134: RESPONSABILIDAD PATRIMONIAL DEL ESTADO. ES IMPROGEDENTE LA CONDENA AL PAGO DE DAÑOS PUNITIVOS.

8 Pues el mero hecho de que se cumplan las anteriores categorías no es garantía de obtener una condena punitiva (Wilcox 2009, 25).

Esta obra está bajo una Licencia Creative Commons Atribución-NoComercial-SinDerivar 4.0 Internacional, IIJ-UNAM. Boletín Mexicano de Derecho Comparado, núm. 157, enero-abril de 2020, pp. 221-242. 
Generalmente, se consideran dos requisitos para la procedencia de los daños punitivos:

a) Conducta excepcional, insultante, insolente de parte del demandado al cometer el hecho generador del daño o en los momentos subsecuentes a ello.

b) Angustia sufrida por la víctima (Sebok y Wilcox 2009, 259).

\section{Punitive damages en los Estados Unidos}

Como se adelantaba líneas arriba, a pesar de que el sistema de los daños punitivos en los Estados Unidos deriva del derecho inglés, se ha desarrollado de forma independiente de él, y ha tenido una evolución propia (Koziol 2009).

Los punitive damages son definidos en el Restatement of Torts (The American Law Institute 2000) como aquellos daños, además de los compensatorios o nominales, otorgados contra una persona para castigarla por su conducta indignante y para disuadir a ella y a otros como ella de una conducta similar en el futuro. Asimismo - añade el Restatement -, los daños punitivos pueden otorgarse por una conducta que es indignante, debido al malvado motivo del acusado o su indiferencia imprudente hacia los derechos de los demás. Al evaluar los daños punitivos - termina diciendo el Restatement - el investigador puede considerar adecuadamente el carácter del acto del demandado, la naturaleza y el alcance del daño al demandante que el acusado causa o la intención de causar y la riqueza del acusado.

Como se desprende de la simple lectura del concepto, su finalidad es castigar al demandado por su conducta indignante y prevenirla en el futuro. En palabras de Sebok (2009, 155):

... un jurado (o juez, bajo ciertas circunstancias) puede, a su discreción, condenar daños punitivos en los casos en que se encuentre que el acusado ha lesionado intencional o maliciosamente al demandante, o en el cual la conducta del acusado reflejó una conducta consciente, imprudente, voluntaria, indiferente u opresiva de los derechos o intereses del demandante. Ningún Estado permite daños punitivos en una demostración de simple o mera negligencia. 
De esta forma, los punitive damages pueden ser impuestos, según la tradición estadounidense, cuando el demandante se comportó de manera intencional o maliciosa, o cuando su conducta refleja una consciente, temeraria, sin sentido u opresiva, indiferencia hacia los derechos o intereses de la víctima, sin que puedan ser impuestos en casos de mera negligencia.

Los punitive damages son actualmente uno de los temas más controversiales del derecho de daños en los Estados Unidos (Sebok 2009), sumado a que la multiplicidad de jurisdicciones estatales impiden hacer una teoría general de los punitive damages, e inclusive cinco estados los prohíben (Louisiana, Massachusetts, Nebraska, Nueva Hampshire y Washington). ${ }^{9}$

El monto de los punitive damages es determinado por el jurado según las consideraciones de seriedad del actuar y gravedad del daño y el patrimonio del deudor, tratando siempre de que su monto sea el razonablemente necesario "to vindicate de state's legitimate interest in punishment and deterrence" (BMW of North America Inc. vs. Gore 1996).

La constitucionalidad de los daños punitivos ha sido cuestionada constantemente, sobre todo en relación con la XIV Enmienda, sección primera, que señala: "tampoco podrá ningún Estado privar a una persona de su vida, libertad o propiedad, sin un debido proceso legal; ni negar a persona alguna dentro de su jurisdicción la protección legal igualitaria". Para valorar la constitucionalidad de los daños punitivos, se han establecido los siguientes criterios (BMW of North América Inc. vs. Gore 1996; Salvador 2000, 6):

a) El grado de reprochabilidad de la conducta del demandado, lo cual es quizá el más importante indicio de la razonabilidad de la condena por daños punitivos. Tal como lo ha establecido la Corte desde hace cerca de 150 años, los daños punitivos deben reflejar la dimensión de su ofensa - the enormity of his offense- (BMW of North America Inc. vs. Gore 1996).

b) Razonabilidad de la relación entre el importe de los daños compensatorios y los daños punitivos. La segunda y quizá el indicio más citado de una condena por daños punitivos irracional o excesiva es la ratio del daño infringido al demandado. El principio de que

9 Massachusetts y Washington sólo los permiten si hay una ley específica que los conceda. 
los daños punitivos deben tener una reasonable relationship con los daños compensatorios tiene un long pedigree (BMW of North America Inc. vs. Gore 1996).

En este punto, es interesante señalar una resolución de la Corte Suprema de los Estados Unidos (State Farm Mutual Automobile Insurance Co. vs. Campbell 2003), que establece que una ratio superior a un dígito (es decir, que los daños punitivos excedan en diez veces los daños compensatorios), solamente sería justificable en casos claramente excepcionales (Ruiz 2007). Lo normal es que la ratio entre los daños compensatorios y los daños punitivos no sea específicamente grande, ya que los pocos casos donde se eleva son en su mayoría reducidos en apelación, y en muchos casos finalmente prevalece de 1:1 (Sebok 2009).

c) El alcance de las sanciones penales establecidas por las leyes para conductas similares, pues "el comparar el monto de la condena por daños punitivos y las penas civiles o penales que podrían imponerse a una conducta similar, provee un tercer indicio de exceso en la condena" (BMW of North America Inc. vs. Gore 1996). Si existe una diferencia considerable entre las penas establecidas para casos similares y el monto impuesto por concepto de daños punitivos, puede evidenciar una inconstitucionalidad por violación a la XIV Enmienda de la Constitución de los Estados Unidos, que arriba indicamos.

Estadísticamente, el 85\% de los casos de condena por daños punitivos se concentra en dos tipos de asuntos: daños intencionales y financial torts. El menor porcentaje está en daños personales por grave negligencia, responsabilidad por productos defectuosos o responsabilidad médica (Sebok 2009, 158).

El doctrinista español Pablo Salvador (2000) sintetiza los aspectos esenciales de los punitive damages en los siguientes puntos:

a) Todos los estudios coinciden en que la proporción y el importe de los veredictos condenatorios de punitive damages son bajos.

b) El importe de la indemnización sancionatoria covaría con la gravedad del daño. 
c) El número e importe de las indemnizaciones de punitive damages varía significativamente en función de la jurisdicción.

d) Los mayores incrementos en los veredictos sancionatorios tienen lugar en pleitos contra empresas por pérdidas puramente económicas causadas dolosamente y no en casos de reclamos por daños corporales.

e) Los veredictos son frecuentemente objeto de revisión judicial; sólo la mitad resultan confirmados en apelación.

f) La media aritmética de las indemnizaciones en los casos de reclamaciones contra empresas duplica la media en los casos contra particulares.

g) Los daños punitivos sancionan conductas antisociales, pues por lo general no se conceden en casos de mera negligencia o culpa.

h) Hay una relación significativa entre su importe y el rol social del demandado.

Finalmente, debemos resaltar que los punitive damages, tanto en derecho inglés como en el estadounidense, son considerados además de los compensatorios, es decir, se calculan separadamente unos y otros.

Podemos concluir que, en Inglaterra, actualmente, los daños punitivos sólo proceden en casos muy concretos y con reglas más o menos específicas, mientras que en los Estados Unidos proceden en cualquier ámbito de reclamación de torts, aunque estadísticamente se concentren en ciertas materias, según dejamos anotado.

\section{ANÁLISIS GRÍTICO}

Para entender correctamente la nueva figura introducida por la Suprema Corte de Justicia de la Nación, debemos partir de que no es lo mismo el hecho de considerar la conducta del demandado como un aspecto para cuantificar el monto de la condena por daño moral - tema señalado por la sentencia materia del presente comentario - que los punitive damages del derecho anglosajón.

Analizando conjuntamente lo señalado por el Código Civil del Distrito Federal y la sentencia de la Primera Sala de la Suprema Corte de Justicia de la Nación aquí comentada, podemos ver que los "daños punitivos" 
a que se refiere la sentencia y los correspondientes criterios no coinciden con los punitive damages de la jurisprudencia estadounidense y británica.

En efecto, el artículo 1916 del Código Civil del Distrito Federal arriba transcrito señala que deberá considerarse para calcular el monto de la indemnización por daño moral, entre otros aspectos, el grado de responsabilidad del demandado; esto es, se trata de un elemento entre varios (los derechos lesionados, la situación económica del responsable y la de la víctima, así como las demás circunstancias del caso), a considerar para determinar la indemnización (Flores 2017), exclusivamente en el tema del daño moral.

Estamos ante la situación de tomar en cuenta aquí el grado de responsabilidad del demandado; es decir, la gravedad de su conducta, de modo que ante un eventual caso donde la conducta del demandado fuera una negligencia sumamente grave, deberá incrementarse la indemnización respecto a un caso donde sólo mostró una culpa leve. Creemos que esto es, en pocas palabras, lo que propone la Suprema Corte de Justicia de la Nación, lo cual nos parece correcto, considerando la literalidad del artículo 1916 del Código Civil del Distrito Federal; sin embargo, consideramos que esto está lejos de equipararse a los punitive damages de la jurisprudencia anglosajona.

Esto es, lo que señala el Código Civil para el Distrito Federal es un factor a considerar, entre otros, con el fin de fijar la indemnización compensatoria del daño moral causado, ya que ni la Ley ni la propia sentencia permiten imponer una eventual indemnización que supere el monto del daño efectivamente causado, pues ello contravendría el texto de los artículos 1910 y 2110 del Código Civil del Distrito Federal.

En la mayoría de los países que comparten nuestra tradición jurídica de origen latino, la función principal de la responsabilidad civil consiste en asegurar a la persona lesionada la reparación del daño (Viney y Jourdain 2010); esto es, "la función primaria de todo sistema de responsabilidad civil es de naturaleza reparatoria o compensatoria: proporcionar a quien sufre un daño injusto los medios jurídicos necesarios para obtener una reparación o compensación" (Reglero 2006, 75).

De esta forma, tenemos que, en principio, la responsabilidad civil no está llamada a cumplir una función preventiva ni punitiva, ya que "es indiscutible que, en lo fundamental, la función disuasoria de las conductas potencialmente dañosas que alcancen un determinado grado de intolera- 
bilidad corresponde a los órdenes penal y administrativo" (Reglero 2006, 82), sin perjuicio de que una y otra función pueda desempeñar un papel secundario o complementario (Reglero 2006).

Consideramos que ésta debe ser entonces la función principal de la responsabilidad civil: reparar los daños causados, según lo establece el artículo 1910 del Código Civil del Distrito Federal, mientras que la punición o prevención serán consecuencias secundarias o colaterales.

Bajo esta lógica es que debemos ubicar la interpretación del Código Civil para el Distrito Federal, en particular del artículo 1916, pues el tema de la gravedad de la culpa se inserta en el tema de la cuantificación del monto de la indemnización, cuando señala que "El monto de la indemnización lo determinará el juez tomando en cuenta...".

Esto es, la idea de indemnización (reparación) del daño va de la mano de la preminencia, al menos de facto, de la indemnización pecuniaria (Viney y Jourdain 2010). Sin embargo, en el caso particular de los daños morales, la reparación en sentido estricto - sea en dinero o por cualquier otra vía - resulta frecuentemente imposible y, en todo caso, se deberá acudir a la idea de "satisfacción" o de "consolación" dada la víctima, para contrarrestar los desagrados y sufrimientos padecidos (Viney y Jourdain 2010).

Es diferente la indemnización por daños punitivos, en el sentido empleado por los sistemas jurídicos anglosajones (superior a los daños realmente sufridos por la víctima) que una valoración de los daños con un criterio que incluya la gravedad de la culpa. Según dejamos anotado líneas arriba, en el common law los daños puramente compensatorios son cuantificados separadamente de los punitivos, mientras que en nuestro sistema el tema de la conducta del demandado es un aspecto a ser considerado para determinar una indemnización única, que según anotamos también líneas arriba, está limitada a los daños sufridos, según los artículos 1910 y 2110 del Código Civil para el Distrito Federal.

Dice Ricardo de Ángel (2012) que el daño puede ser valorado, al llevar a cabo la estimación, mediante criterios distintos, y por ello compensado con una cantidad diversa (superior) en el caso de una culpa mayor; pero eso es muy diferente a los punitive damages del derecho estadounidense (Vargas 2004).

Cuando la Suprema Corte de Justicia de la Nación habla de que la responsabilidad civil tiene una función castigadora, no debe entenderse 
desde una perspectiva que comprenda un sobre, pago de un daño, sino que se refiere a que ese pago por el daño causado en sí mismo — y nada más que ese daño causado - tiene una función punitiva, precisamente por esa obligación de pago, no por una suma extra con carácter sancionador, como sí lo hace el sistema anglosajón. ${ }^{10}$

Ahondando en esta línea de pensamiento, Viney y Jourdain (2010) dicen que dentro de la idea de pena privada hay varias opciones. La más típica es la de los punitive damages; pero hay otras diversas, de manera que no toda figura que considere la conducta del demandado para agregar al monto de la indemnización es un daño punitivo, y mucho menos en el sentido que el derecho estadounidense. De forma que considerar el elemento punitivo de la conducta del responsable en la tasación del daño no necesariamente equivale a un daño punitivo en el sentido estadounidense e inglés, a un daño extracompensatorio.

Finalmente, debemos resaltar que todo el argumento y razonamiento de la sentencia en comento gira en torno al artículo 1916 del Código Civil para el Distrito Federal, lo cual ubica a los "daños punitivos" en el exclusivo ámbito de los daños morales, no habiendo precepto alguno que permita su aplicación o, al menos, la consideración de la conducta del demandado, a los daños puramente patrimoniales, lo cual es otro aspecto que marca una profunda diferencia con los punitive damages del sistema anglosajón.

De esta forma, podemos concluir que lo que señala la sentencia dictada en el Amparo directo 30/2013 por la Primera Sala de la Suprema Corte de Justicia de la Nación no son punitive damages en el sentido de la jurisprudencia estadounidense e inglesa, sino que se refiere más bien al aspecto punitivo — secundario, según anotamos - de la reparación del daño moral, lo cual estará siempre determinado o limitado por la función

10 Parece que así es la interpretación dada por la propia Primera Sala de la Suprema Corte al resolver los amparos directos 35/2014 y 39/2015, y en especial el Amparo directo en revisión 593/2015, que en su párrafo 116 señala: "En ese tenor, si bien en los amparos directos 30/2013 y 31/2013, esta Suprema Corte aceptó la aplicabilidad de la faceta de los «daños punitivos» al indemnizar el daño moral previsto en el artículo 1916 del Código Civil para el Distrito Federal, eso se hizo en atención a las propias reglas de la reparación de ese tipo de daño que permite adecuar la faceta punitiva a las peculiaridades y hechos de cada caso concreto". 
primaria indemnizatoria, reparatoria o compensatoria de la responsabilidad civil.

\section{BIBLIOGRAFÍA}

Ángel, Ricardo de. 2012. Daños punitivos, Pamplona, Civitas-Thomson Reuters.

Brooke, Sir Henry. 2009. "A Brief Introduction: The Origins of Punitive Damages", en KozIol, Helmut y Wilcox, Vanessa (eds.), Punitive Damages: Common Law and Civil Law Perspectives, Viena, Springer, VienaNueva York.

FLORES, E. Lucía. 2017. "Evolución histórica del daño moral a daños punitivos", Revista Mexicana de Historia del Derecho, vol. XXXVI.

García, Laura Victoria y HerrerA, María Carolina. 2003. "El concepto de los daños punitivos o punitive damages", Revista de Estudios Socio-furídicos $5(1)$.

KozIOL, Helmut. 2009. "Punitive Damages: Admission into the Seventh Legal heaven or Eternal Damnation? Comparative Report and Conclusions", en KozIol, Helmut y Wilcox, Vanessa (eds.), Punitive Damages: Common Law and Civil Law perspectives, Viena, Springer, VienaNueva York.

MaBride, Nicholas J. y BAGSHAW, Roderick. 2018. Tort Law, Londres, Pearson.

Muñoz, Edgardo y VÁzQuez-Gabello, Rodolfo. 2019. "New Punitive Damages in Mexican Law- Or the Chronicle of a Failed Legal Transplant Foretold?", Hastings International and Comparative Law Review, 42 (203).

Prosser, William L. et al. 2010. Torts, Cases and Materials, Nueva York, Thomson-Reuters.

Reglero Campos, L. Fernando. 2006. "Conceptos generales y elementos de delimitación", en Reglero Campos, L. Fernando (coord.), Tratado de responsabilidad civil, Gizur Menor.

RuIZ, Juan Antonio. 2007. "Otra vuelta de tuerca a los daños punitivos", In Dret, núm. 2.

SAlvadOR, Pablo. 2000. "Punitive damages", InDret, núm. 1. 
SeboK, Anthony J. 2009. "Punitive Damages in the United States", en

Koziol, Helmut y Wilcox, Vanessa (eds.), Punitive damages: Common Law and Civil Law perspectives, Springer, Viena-Nueva York.

SEBoK, Anthony J. y WiLcox, Vanessa. 2009. "Aggravated damages", en

Koziol, Helmut y Wilcox, Vanessa (eds.), Punitive Damages: Common Law and Civil Law perspectives, Springer, Viena-Nueva York.

The American Law Institute. 2000. A Concise Restatement of Torts, St. Paul, Minnesota, American Law Institute Publishers.

VArGas, Jorge A., 2004. "Moral Damages under the Civil Law of Mexico. Are These Damages Equivalent to U.S. Punitive Damages?", Miami Inter-American Law Review, 35 (183).

VINEY, Geneviéve y JOURDAIn, Patrice. 2010. Les effets de la responsabilité, París, Librairie General de Droit et Jurisprudence.

Wilcox, Vanessa. 2009. "Punitive damages in England", en KozIOL,

Helmut y Wilcox, Vanessa (eds.), Punitive Damages: Common Law and Civil Law Perspectives, Springer, Viena-Nueva York. 